\title{
6360 Sayılı Kanunun Kamu Hizmetlerinin Sunumuna Etkisi: İncirliova Belediyesi Örneği
}

\author{
Fatma Neval Genç \\ Adnan Menderes Üniversitesi Nazilli İ̈BF, Siyaset Bilimi ve Kamu Yönetimi Bölümü, Nazilli, Aydın \\ fngenc@adu.edu.tr \\ ORCID ID: 0000-0003-2014-2113 \\ Hüseyin Özerk \\ İncirliova Belediyesi, İncirliova, Aydın \\ huseyinozerk@hotmail.com \\ ORCID ID: 0000-0001-6869-3841

\section{Mehmet Sefa Ülkü} \\ Adnan Menderes Üniversitesi Sosyal Bilimler Enstitüsü Siyaset Bilimi ve Kamu Yönetimi Programı, Nazilli, Aydın \\ mehmetsafa09@gmail.com \\ ORCID ID: 0000-0003-2631-3091
}

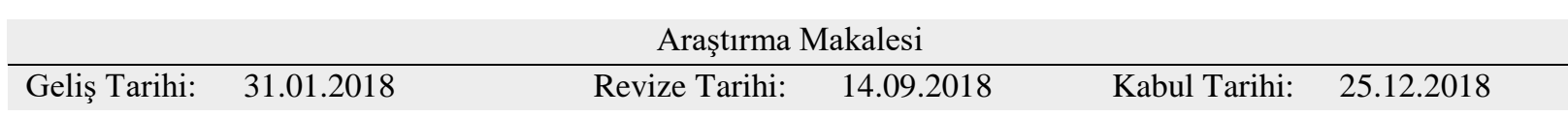

\section{Atıf Bilgisi}

Genç, F. N., Özerk, H. ve Ülkü, M. S. (2018). 6360 sayılı kanunun kamu hizmetlerinin sunumuna etkisi:

İncirliova Belediyesi örneği, Ahi Evran Üniversitesi Sosyal Bilimler Enstitüsü Dergisi, 4(2) 207-221.

\section{öz}

6360 sayılı kanunun amaçları arasında ölçek ekonomisinden faydalanmak, kamu hizmetlerinin sunumunda etkinlik ve verimliliği artırmak, koordinasyon eksikliğini gidermek, ulaşım, çevre ve sanayileşmenin neden olduğu sorunları çözmek yer almaktadır. Bu kapsamda büyükşehir olma kriterleri değiştirilmiş, büyükşehir sayısı 30'a çıkarılmış ve büyükşehirlerdeki köyler ve belde belediyeleri mahalle olarak ilgili belediyeye bağlanmıştır. Aydın da 6360 sayılı kanunla büyükşehir statüsü elde etmiştir. Bu çalışmanın amacı, yeni büyükşehirlerde kanunun amaçlarına ne derece ulaşıldığını ilçe belediyeleri açısından incelemektir. Çalışmada literatür taraması yanında anket ve görüşme formları veri elde etmek için kullanılmıştır. Bu amaçla Aydın'ın İncirliova ilçe belediyesi örneğinde belediye başkanı, başkan yardımcıları, meclis üyeleri ve mahalle muhtarları (toplam 49 kişi) üzerinde 6360 sayılı kanuna ilişkin algılarını ölçmek üzere bir anket uygulanmıştır. Ankette elde edilen sonuçlar göstermektedir ki; İncirliova ilçe belediyesinde belediye yöneticileri ve muhtarlar 6360 sayılı kanun sonrasında ortaya çıkan durumu genellikle olumsuz olarak değerlendirmektedir.

Anahtar Kelimeler: 6360 sayılı kanun, Aydın, İncirliova, kamu hizmeti sunumu, ilçe belediyeleri.

\section{The Impact of Law No. 6360 on the Provision of Public Services: The Case of İncirliova Municipality}

\begin{abstract}
Among the purposes of Law No. 6360 are, to benefit from economies of scale, to improve effectiveness and efficiency in public service provision, to eradicate the lack of coordination, to solve the problems caused by transportation, environment and industrialization. In this context, the criteria of being a metropolitan city were changed, the number of metropolitan cities was increased to 30 , and villages and township municipalities in metropolitan areas were connected to the relevant municipality as neighborhoods. The city of Aydın has also obtained the metropolitan status with the law numbered 6360 . The aim of this study is to examine the extent to, which the new metropolitans are attaining the purposes of the new law, in terms of district municipalities. In the study, in addition to the literature review, questionnaires and interview forms were used to obtain data. For this purpose, a questionnaire was done with the mayor, deputy mayor, councilors and neighborhood muhtars (total 49 persons) of Aydın's Incirliova district municipality. The results obtained in the survey show that, in Incirliova district municipality, municipality officials and muhtars generally evaluate the situation that emerged after Law 6360, negatively.
\end{abstract}

Keywords: Law no. 6360, Aydın, İncirliova, public service provision, district municipalities. 


\section{Giriş}

2004 yılında yürürlüğe giren 5216 sayılı kanunla il mülki sınırında büyükşehir belediye modelinin getirilmesi; 2008 yılında çıkarılan 5747 sayılı kanun ile bu modelin güçlendirilmesi ve 2012'de kabul edilen 6360 ve 6447 sayll kanunlar ile önceden sadece İstanbul ve Kocaeli'nde uygulamaya konulan modelin tüm büyükşsehir belediyelerine yaygınlaştırılması, Türkiye'de büyükşehir sisteminde önemli değişikliklere neden olmuştur.

6360 sayılı kanunla, büyükşehir belediyesinin uygulama alanı, il ölçeği olarak belirlenmiş, büyükşehir belediye, belediye, köy ve il özel yönetiminin bütünleştirileceği bir yerel yönetim yapısı oluşturulmuş; büyükşehir belediyelerine sadece kentleri değil, ilin mülki idare sınırlarından oluşan büyük bir mekânı yönetme imkânı getirilmiş; dolayısıyla mekânsal alan yönetimine geçilmiştir. $\mathrm{Bu}$ modelin uygulanacağı illerde bazı yerel yönetim birimlerinin tüzel kişiliği kaldırılarak, büyükşehir belediyelerinin buralarda tek yetkili birim olarak yönetimde olması amaçlanmıştır (Yıldırım vd., 2015: 223). Bu değişimin kamu hizmet sunumunda ortaya çıkaracağı sonuçlar süreç içerisinde somut olarak görülecektir.

6360 sayılı kanun, büyükşehir tanımını değiştirmiştir. Yeni kanuna göre büyükşehir belediyesi, "Sınırları il mülki sınırı olan ve sınırları içerisindeki ilçe belediyeleri arasında koordinasyonu sağlayan; idarî ve malî özerkliğe sahip olarak kanunlarla verilen görev ve sorumlulukları yerine getiren, yetkileri kullanan; karar organı seçmenler tarafından seçilerek oluşturulan kamu tüzel kişisini” ifade etmektedir (m.4). Tanıma göre, büyükşsehir belediyesi sınırları ilin mülki sınırlarını kapsamaktadır. Yeni kanun, "toplam nüfusu 750.000'den fazla olan illerin il belediyeleri kanunla büyükşsehire dönüştürülebilir" biçimindeki düzenlemesiyle, büyükşehir belediyesi kurulması için gerekli olan nüfus ölçütünde, artık ilin toplam nüfusunun dikkate alınacağını belirtmektedir.

Aydın da 6360 sayılı kanunla büyükşehir olan illerden biridir. Büyükşehir Kanununun yürürlüğe girmesiyle Aydın Büyükşehir Belediyesi ve ilçe belediyeleri arasında görev paylaşımı yapılmıştır. Buna göre ilçe belediyeleri; tüm ilçe alanın ruhsat işlerini, $4000 \mathrm{~m} 2$ altı park bahçe ve meydanların bakım hizmetlerini, genişliği 12 metre ve altı cadde ve sokakların yol çalışma, kaldırım yapımı ve tamirat ile temizlik hizmetlerini, nikâh işlemlerini, tüm ilaçlama hizmetlerini, ilçe alanındaki mezarlık ve defin hizmetlerini yapacaklardır.

Bu çalışmanın inceleme alanını Aydın İli’nin İncirliova İlçesi oluşturmaktadır. Bu kapsamda çalışmada cevabı aranan soru İncirliova Belediyesi'nde belediye yöneticileri, eski ve yeni mahalle muhtarları açısından büyükşehir uygulamasından beklenen sonuçların (etkinlik, verimlilik, imar, ulaşım ve altyapı planlamada bütünlük; personel ve kaynak tasarrufu, koordinasyon kolaylığı vb) ortaya çıkıp çıkmadığıdır.

\section{Yöntem}

Literatürde 2012 y1lında kabul edilen ve 2014 Mart ayından itibaren uygulamada olan 6360 sayılı kanunla alakalı yapılmış çalışmalar olmakla beraber, bunlar arasından alan araştırmasına dayalı olanlar az sayıdadır Adıgüzel (2012), Bahadır (2017), Genç (2014), Genç ve Daşcı (2016), Genç ve Korkin (2017), Karayel (2016), Sezik (2015), Zengin (2014). 6360 sayılı kanun çerçevesinde İncirliova İlçesi üzerinde yapılan bir çalışma bulunmamaktadır.

Çalışmanın evrenini, 6360 sayılı kanunla büyükşsehir belediyesi statüsü kazanan 30 büyükşehir belediyesi oluştururken, örneklemini Aydın İli İncirliova ilçesi oluşturmaktadır. Çalışmada İncirliova İlçesinde mahalle muhtarları (eski ve yeni toplam 28 muhtar) ve belediye başkan, başkan yardımcıları ve meclis üyelerinden oluşan (toplam 18) 46 kişiye görüşme formu ve Likert tipi (3 seçenekli) anket kullanılarak ulaşılmıştır. Anket formu 9'u demografik soru ile 45'i araştırma sorusu olmak üzere toplam 54 sorudan oluşmuştur.

\section{Bulgular}

Bu başlık altında 6360 sayılı kanunla Aydın Büyükşehir Belediyesinin ilçe belediyesi haline gelen İncirliova Belediyesinde ortaya çıan idari ve mali durum ile İncirliova ilçe belediye başkan, başkan yardımcıları, belediye meclis üyeleri ve mahalle muhtarları ile yapılan anket ve görüşmelerden elde edilen sonuçlar yer alamaktadır. 


\section{Sayılı Kanunla İncirliova'da Ortaya Çıkan Durum}

Ege Bölgesinde yer alan Aydın ilk çağlardan beri verimli toprakları, elverişli, iklimi, ticaret yolları üzerinde bulunması nedeniyle önemli bir yerleşim merkezi olmuş; tarihi süreç içerisinde çeşitli uygarlıklara ev sahipliği yapmış ve bugün de bunların izlerini taşımaktadır ${ }^{1}$. Aydın ekonomisi tarım, sanayi, dış ticaret ile turizm faaliyetlerine dayanmaktadır. 2016 yılı adrese dayalı nüfus sayımı sistemi ne göre Aydın ili nüfusu 1068260 olarak belirlenmiştir (TÜİK, 2016). 2016 itibariyle İncirliova'nın nüfusu 49.169'dur. İl merkezine uzaklığı 10 km'dir.

İncirliova Aydın'ın 17 ilçesinden biridir. Aydın'ın 7 ilçesi Cumhuriyet öncesinde kurulmuş, diğerleri ise 1940'lı yılların sonundan itibaren kurulmaya başlanmıştır. İncirliova ilçesi 1400'lü yıllardan beri yerleşim yeridir. İncirliova 1867 yılında bucak olmuş, 1898 yılında da belediye teşkilatı kurulmuştur; o zamanki adı Karapınar iken 1942 yılında İncirliova olarak değiştirilmiştir. 04.07.1987 tarihinde 04.07.1987-19507 sayılı resmi gazetede 3392 sayılı kanunda yer alarak ilçe olmuştur.

İncirliova, doğuda Aydın merkez, batıda Germencik, kuzeyde İzmir'in Tire İlçesi, güneyde ise Büyük Menderes Nehri ve Koçarlı İlçesi ile çevrili; 185.012 dekar alana sahip hızla büyüyen bir ilçedir. Konum olarak Aydın'a yakın olmasından dolayı ilçenin tarihi, kentsel ve ekonomik gelişimi Aydın ile bütünlük arz eder.

6360 sayılı Kanunla Aydın'ın 17 ilçesinin idari ve mali yapısında değişiklikler meydana gelmiştir. 6360 sayılı kanun sonrasında İncirliova'da 21 köyün (Akçeşme, Arapdere, Arzular, Beyköy, Dereağzı, Eğrek, Erbeyli, Gerenkova, Hacıaliobası, Hamitler, İkizdere, İsafakılar, Köprüova, Osmanbükü, Sandıklı, Şirindere, Yazıdere; Sınırteke, Palamutköy, Karagözler, Karabağ) tüzel kişiliği kaldırılarak mahalleye dönüştürülmüş, Acarlar Belde Belediyesinin de tüzel kişiliği kaldırılarak İncirliova Belediyesine tek mahalle olarak bağlanmıştır (Genç, 2014).

6360 sayılı kanun sonrasında İncirliova'nın mali yapısında da bazı değişikliler meydana gelmiştir. 6360 sayılı kanun öncesinde İncirliova Belediyesinin sorumlu olduğu alan $7.8 \mathrm{~km}^{2}$ iken kanun sonrası bu alan ilçe mülki sınırı olan $214 \mathrm{~km}^{2}$ 'ye çıkmış, belediyenin kaynağı artmış gibi görünse de ASKİ ve Büyükşehir kesintileri düşüldüğünde mali kaynaklarının azaldığı ortaya çıkmıştır. 6360 sayılı Kanundan önce belde belediyesi olan Acarlar'in $3.05 \mathrm{~km}^{2 ‘}$ lik sorumluluk sahası olan alanda aldığ kaynak, kanundan sonra mahalleye dönüşmesiyle ortadan kalmıştır. 2013 yılında Acarlar ve İncirliova Belediyelerinin gelirleri (10.85 km² için) 9.463.885,90 TL iken 2015 yılı geliri $\left(214 \mathrm{~km}^{2}\right.$ için) 7.781.514,37 TL' ye düşmüştür.

6360 say1lı kanun sonrasında İncirliova'da köyden mahalleye dönüşen yerleşim yerlerinin Aydın il merkezine olan uzaklıklarının 11-32 km arasında değişmekte olduğu ve İncirliova ilçe merkezine olan uzaklıklarının 1-24 km arasında olduğu görülmektedir. Bu idarelerin mali yapılarını ortaya koymak amacıyla köy yönetimi iken herhangi bir gelire sahip olup olmadığı, daha önce salma ve imece uygulanıp uygulanmadığı incelenmiş ve Tablo 1'de gösterilmiştir.

\footnotetext{
1 M.Ö. XIII. yüzyılda bölgede Hitit egemenliğinin kalkmasından Türk hâkimiyetine kadar geçen süreçte Aydın'da sırasıyla Frigler, Lidyalılar, İonlar, Persler, Büyük İskender, Romalılar ve Bizanslılar hüküm sürmüşlerdir. Karabağ, Erbeyli ve Köprüovası yerleşimlerinde (eski köylerde) arkeolojik kalıntılara rastlanmaktadır. Menteşe Beyliği toprağı olan Aydın ve çevresi 1310 yılından itibaren Aydınoğulları Beyliği hâkimiyetinde iken, 1426 yılında Osmanlı egemenliğine geçmiştir.
} 
Tablo 1.

6360 Sayll Kanun Öncesi Incirliova’ya Bağlı Belde ve Köylerin Gelirleri

\begin{tabular}{|c|c|c|c|c|c|c|c|c|}
\hline $\begin{array}{l}\text { Sira } \\
\text { Nu. }\end{array}$ & $\begin{array}{c}\text { Eski Belde } \\
\text { (Acarlar) ve } \\
\text { Köyler } \\
\text { (Yeni Mahalleler) }\end{array}$ & $\begin{array}{l}\text { Nüfus } \\
\text { (2016) }\end{array}$ & $\begin{array}{c}\text { İl } \\
\text { Merkezine } \\
\text { Uzaklık }\end{array}$ & $\begin{array}{c}\text { İlçe } \\
\text { Merkezine } \\
\text { Uzaklık }\end{array}$ & Rakım & $\begin{array}{c}\text { Köy } \\
\text { Yönetimi } \\
\text { İken Y1llık } \\
\text { Geliri TL } \\
\end{array}$ & $\begin{array}{c}\text { Salma } \\
\text { Uygulam } \\
\text { a }\end{array}$ & $\begin{array}{c}\text { İmece } \\
\text { uygulama }\end{array}$ \\
\hline 1 & acarlar & 11485 & $12 \mathrm{~km}$ & $4 \mathrm{~km}$ & $30 \mathrm{~m}$ & $3.423 .849,72$ & \multicolumn{2}{|c|}{ Belde Belediyesi } \\
\hline 2 & akçeşme & 297 & $17 \mathrm{~km}$ & $7 \mathrm{~km}$ & $60 \mathrm{~m}$ & 30.000 & - & + \\
\hline 3 & arpadere & 378 & $27 \mathrm{~km}$ & $17 \mathrm{~km}$ & $30 \mathrm{~m}$ & 30.000 & - & + \\
\hline 4 & arzular & 275 & $20 \mathrm{~km}$ & $10 \mathrm{~km}$ & $174 \mathrm{~m}$ & 50.000 & - & + \\
\hline 5 & atatürk & 1738 & $11 \mathrm{~km}$ & Merkez & $30 \mathrm{~m}$ & - & - & - \\
\hline 6 & beyköy & 452 & $18 \mathrm{~km}$ & $24 \mathrm{~km}$ & $605 \mathrm{~m}$ & 50.000 & - & + \\
\hline 7 & cumhuriyet & 9867 & $11 \mathrm{~km}$ & Merkez & $30 \mathrm{~m}$ & - & - & - \\
\hline 8 & dereağz1 & 628 & $14 \mathrm{~km}$ & $4 \mathrm{~km}$ & $65 \mathrm{~m}$ & 20.000 & - & + \\
\hline 9 & eğrek & 430 & $25 \mathrm{~km}$ & $15 \mathrm{~km}$ & $400 \mathrm{~m}$ & 30.000 & - & + \\
\hline 10 & erbeyli & 1159 & $15 \mathrm{~km}$ & $5 \mathrm{~km}$ & $52 \mathrm{~m}$ & 150.000 & - & - \\
\hline 11 & gerenkova & 1983 & $11 \mathrm{~km}$ & $1 \mathrm{~km}$ & $45 \mathrm{~m}$ & 100.000 & - & - \\
\hline 12 & hacıaliobası & 987 & $12 \mathrm{~km}$ & $2 \mathrm{~km}$ & $28 \mathrm{~m}$ & 100.000 & - & + \\
\hline 13 & hamitler & 16 & $18 \mathrm{~km}$ & $8 \mathrm{~km}$ & $250 \mathrm{~m}$ & 40.000 & - & + \\
\hline 14 & hürriyet & 3005 & $11 \mathrm{~km}$ & Merkez & $30 \mathrm{~m}$ & - & - & - \\
\hline 15 & ikizdere & 315 & $19 \mathrm{~km}$ & $9 \mathrm{~km}$ & $140 \mathrm{~m}$ & 15.000 & - & + \\
\hline 16 & isafakılar & 335 & $32 \mathrm{~km}$ & $22 \mathrm{~km}$ & $530 \mathrm{~m}$ & 15.000 & - & + \\
\hline 17 & istiklal & 3921 & $11 \mathrm{~km}$ & Merkez & $30 \mathrm{~m}$ & - & - & - \\
\hline 18 & karabağ & 385 & $14 \mathrm{~km}$ & $4 \mathrm{~km}$ & $140 \mathrm{~m}$ & 25.000 & - & + \\
\hline 19 & karagözler & 299 & $26 \mathrm{~km}$ & $19 \mathrm{~km}$ & $525 \mathrm{~m}$ & 10.000 & - & + \\
\hline 20 & köprüova & 133 & $25 \mathrm{~km}$ & $15 \mathrm{~km}$ & $200 \mathrm{~m}$ & 10.000 & - & + \\
\hline 21 & kurtuluş & 2630 & $11 \mathrm{~km}$ & Merkez & $30 \mathrm{~m}$ & - & - & - \\
\hline 22 & osmanbükü & 958 & $7 \mathrm{~km}$ & $6 \mathrm{~km}$ & $42 \mathrm{~m}$ & 600.000 & - & - \\
\hline 23 & palamutköy & 166 & $26 \mathrm{~km}$ & $16 \mathrm{~km}$ & $30 \mathrm{~m}$ & 5000 & - & + \\
\hline 24 & sandikl1 & 2510 & $9 \mathrm{~km}$ & $1 \mathrm{~km}$ & $39 \mathrm{~m}$ & 120.000 & - & - \\
\hline 25 & sinırteke & 1040 & $15 \mathrm{~km}$ & $5 \mathrm{~km}$ & $35 \mathrm{~m}$ & 100.000 & - & + \\
\hline 26 & şirindere & 235 & $22 \mathrm{~km}$ & $12 \mathrm{~km}$ & $210 \mathrm{~m}$ & 15.000 & - & + \\
\hline 27 & yazıdere & 436 & $15 \mathrm{~km}$ & $5 \mathrm{~km}$ & $30 \mathrm{~m}$ & 70.000 & - & + \\
\hline 28 & zafer & 3106 & $11 \mathrm{~km}$ & Merkez & $30 \mathrm{~m}$ & - & - & - \\
\hline
\end{tabular}

Kaynak: TUİK (2013), Yerel Yönetimler Portalı (2017)

İncirliova'nın geçim kaynağı tarımdır. Muhtarlarla yüz yüze yapılan görüşmelerden alınan bilgilere göre köy tüzel kişiliğinde iken gelirlerini genellikle su, incir, zeytin ( 2 yılda bir), pamuk tarlalarının ve taşınmazların kiralaya verilmesinden sağladıkları tespit edilmiştir. Özellikle Osmanbükü Mahallesinin geliri dikkat çekmektedir. Acarlar Mahallesi ise eskiden belde belediyesi iken mahalleye dönüştürülmüş diğer mahalleler ile karşılaştırma yapmak için tabloda yer verilmiştir. Osmanbükü ve Erbeyli Mahalleleri köy iken personele sahip oldukları, ihtiyaç hâlinde yevmiye usulü ile işlerin gördürüldüğü, bazı yerlerin de herhangi bir personeli olmadığı anlaşılmaktadır. Geliri düşük olan yerlerde hizmet taleplerinin genellikle il özel idaresi tarafından; nadiren de imece usulü ile görüldüğü muhtarlarla yapılan görüşmelerden anlaşılmıştır.

İncirliova'da belediye başkanlığı MHP yönetimindedir. Belediye başkanı dışında 15 kişilik belediye meclisinde 7 MHP'li, 4'er AKP ve CHP'li üye yer almaktadır.

Belediye Yöneticileri ve Muhtarların Gözünden 6360 Sayılı Kanunun İncirliova'da Hizmet Sunumuna Etkisi

Çalışmanın evrenini, 6360 sayılı kanunla büyükşehir belediyesi statüsü kazanan 30 il; çalışmanın örneklemini ise Aydın ili İncirliova ilçesinde eski (6 mahalle) ve yeni 21 (21 eski köyden 17'si ile anket yapılmıştır) muhtar ve belde belediyesi (Acarlar Belde Belediyesinde yer alan 6 
mahalleden 5 tanesi ile anket yapılmıştır) oluşturmaktadır. Çalışmada toplam 28 mahalle muhtarlarıyla anket yapılmıştır. Anket ve görüşmeler Şubat ve Mart 2017 döneminde gerçekleştirilmiştir. Çalışmada ayrıca İncirliova Belediye başkanı, 2 başkan yardımcısı ve 15 belediye meclis üyesi, olmak üzere toplam 18 kişiye anket yöntemiyle sunulan ifadelere katılım durumlarını ölçen bir anket de çalışması uygulanmıştır. Bu şekilde 6360 sayılı kanun ve sonuçları bir yandan muhtarlar bir yandan da belediye yöneticileri gözünden değerlendirilmiş, benzerlik ve farklılık taşıyan görüşler ve bunların nedenleri tespit edilmeye çalışılmıştır. Çalışmada görüşme formu yöntemi ve Likert tipi anket kullanılmıştır. Anket formu 9'u demografik soru ile 45'i araştırma sorusu olmak üzere toplam 54 sorudan oluşmuştur. Araştırma soruları 3 seçenekli Likert tipi anket olarak hazırlanmıştır.

Anketlerden ortaya çıkan sonuçlar şu şekildedir; muhtarlar, belediye başkan ve başkan yardımcıları ve belediye meclis üyelerinin büyük bölümü anket ve görüşme formunda yer alan birkaç ifade dışında çoğunlukla aynı düşünceyi paylaşmaktadır ve genellikle 6360 uygulamaları konusunda düşünceleri, algıları olumsuzdur.

Muhtarlar ve belediye yöneticilerinin büyük bölümünün katıldıkları_görüşler şöyledir:

- Büyükşehir statüsüne geçilmesi yazışmaları/bürokrasiyi artırmıştır.

- Büyükşehir statüsüne geçilmesinin ardından su faturalarından şikâyetler artmıştır.

- Köyden dönüşen mahallelerde ulaşımla alakalı sorunlar yaşanmaktadır.

- Belediyemizin mali özerkliği azalmıştır.

- Belediyemizin sorumluluk sahasının genişlemesi hizmet sunumunda aksamalara neden olmaktadır.

- Büyükşehir yönetimine geçilmesiyle ilçe belediyelerinin büyükşehir belediyesine bağımlılığı artmıştır.

- Büyükşehir yönetimine geçilmesiyle ilçe belediyelerinin temsil imkânı azalmıştır.

- Büyükşehir düzenlemeleri sonrasında halkın altyapı konusundaki şikâyetleri artmıştır.

- Büyükşsehir düzenlemesi sonrasında ilçemizde ulaşım şikâyetleri artmıştır.

- Büyükşehir düzenlemesi sonrasında ilçemizde imar düzenlemeleri konusundaki şikâyetler artmıştır.

- Büyükşehir düzenlemesiyle büyükşehir belediyesi ile aramızda koordinasyon sorunları yaşanmaktadır.

- Büyükşehir belediyesi ile imar yetkilerinin bölüşümünde ve uygulanmasında sorunlar yaşamaktayız.

- Eski köylere/yeni mahallelere hizmet götürme konusunda personel açısından sorunlar yaşamaktayız.

- Yeni mahallelere hizmet götürme konusunda teknik ekipman, araç-gereç sorunu yaşamaktayız.

- Büyükşehir düzenlemesi yerel demokrasi açısından uygun değildir. 
- Eski köyler/yeni mahallelerin ilçe merkezine uzak olması hizmet sunumunu olumsuz etkilemektedir.

- Eksi köyler/yeni mahallelerin ilçe merkezi ile arasında coğrafi engeller hizmet sunumunu olumsuz etkilemektedir.

- Köylerin mahalleye dönüşmesi hizmet etkinliğini azaltmıştır.

- Köylerin mahalleye dönüşmesi tarım ve hayvancılık faaliyetlerini olumsuz etkilemiştir.

- Büyükşehir düzenlemesi merkeziyetçiliği artırmıştır.

- Özellikle eski orman köylerine/yeni mahallelere hizmet götürmede sorunlar yaşamaktayız.

- Büyükşehir belediyesi modeli öncesine geri dönülmelidir.

- Büyükşehir Belediyelerinin ilçelerde yerel hizmet ofisleri açılmalıdır.

- Genel bütçe vergi gelirlerinden ilçe belediyelerine ve büyükşehir belediyesine ayrılan paylar yeniden düzenlenmelidir.

- Mahalli idare birlikleri yeniden kurulmalıdır.

- Köylere tüzel kişilikleri geri verilmelidir.

- Belde belediyelerine tüzel kişilikleri geri verilmelidir.

- Büyükşehir düzenlemesi yerelleşmeyi artırmıştır.

Muhtarlar ve belediye yöneticilerinin büyük bölümünün katılmadıkları görüşler şöyledir:

- Büyükşehir belediyesi sınırlarının il sınırlarına kadar genişlemiş olması vatandaşa daha etkin hizmet sunulması açısından olumlu bir gelişmedir.

- Büyükşehir belediyesi (il) sınırlarındaki köylerin/beldelerin mahalleye dönüştürülmesini uygun buluyorum.

- Büyükşsehir belediyesi (il) sınırlarındaki il özel idarelerinin kapatılmasını uygun buluyorum.

- Büyükşsehir belediyesi (il) sınırlarındaki mahalli idare birliklerinin kapatılmasını uygun buluyorum.

- Büyükşehir statüsüne geçilmesinin imar ve planlama bütünlüğü sağladığını düşünüyorum.

- Büyükşehir belediyesi sınırlarının il sınırlarına kadar genişlemiş olmasının vatandaşa daha etkin hizmet sunulması açısından olumlu bir gelişmedir

- Büyükşehir statüsüne geçilmesinin hizmet maliyetlerini azalttığını düşünüyorum.

- Yatırım İzleme Koordinasyon Başkanlığının çalışmalarını olumlu bulmaktayım.

- Büyükşehir statüsünün yönetici-vatandaş ilişkilerini güçlendirdiğini düşünüyorum.

- Büyükşehir düzenlemesiyle yeni ilçelerin kurulması olumlu olmuştur. 
- Büyükşehir düzenlemesine geçtikten sonra ilçemizde sunulan yerel hizmetlerin verimliliğinin arttığını düşünüyorum.

- Büyükşehir düzenlemesine geçtikten sonra ilçemiz halkının yerel kamu hizmetlerine ulaşımı kolaylaşmıştır.

- Büyükşehir belediyesi düzenlemesiyle İlçe belediyeleri arasında koordinasyon artmıştır.

Özellikle belediye yöneticileri büyükşehir belediyesi ile imar yetkilerinin bölüşümünde ve uygulanmasında; yeni mahallelere hizmet götürmede, teknik ekipman, araç-gereç anlamında yetersizlikler ve mülki idare ile görev ve yetki çatışmaları yaşadıklarını ifade etmektedirler.

Muhtarlar (11 kişi) ve belediye yöneticilerinin (9 kişi) büyük bölümü "Büyükşehir belediyesi statüsüne geçilmesinin ulaşım planlamasında bütünlüğü sağladığını düşünüyorum" ifadesine katılmakla beraber, bu ifadeye katılmayanların sayısı da en az katılanlar (muhtarlarda 10 kişi ve belediye yöneticilerinde 8 kişi) kadar fazla iken kararsız kalanların oranı da muhtarlarda (7 kişi) oldukça yüksektir. Bu durum diğer sorularda yüksek oranda çıkan olumsuz cevaplar karşısında ulaşım planlaması konusunda büyükşehir düzenlemesinden memnun olanların da bulunduğu sonucunu ortaya koymaktadır.

Muhtarların büyük bölümü (n=18 kişi) "Büyükşehir belediyesi statüsüne geçilmesinin altyap1 planlamasında bütünlüğü sağladığını düşünüyorum" ifadesine katılmazken, belediye yöneticileri ( 8 kişi) büyükşsehir uygulaması ile altyapı bütünlügünü sağladığını düşünmektedir.

Muhtarların (24 kişi) ve belediye yöneticilerinin (14 kişi) büyük bölümü "Yatırım izleme Koordinasyon Başkanlığının çalışmalarını olumlu bulmaktayım” ifadesine katılmamaktadır. Olumsuz görüş bildirenlerin birçoğunun böyle bir kuruluşun varlığından haberdar olmadıkları anlaşılmaktadır.

Muhtarların (11 kişi) ve belediye yöneticilerinin (13 kişi) büyük bölümü "Büyükşehir belediyesi düzenlemesiyle yeni ilçelerin kurulması olumlu olmuştur" ifadesine katılmamaktadır. Bu ifadeye katılım açısından 8 muhtarın kararsız, 9 muhtarın ise olumlu görüş bildirmesi, yeni ilçeler konusunda kısmen de olsa memnun olan muhtarların varlığına işaret etmektedir.

Muhtarların (14 kişi) ve belediye yöneticilerinin (17 kişi, 1 kişi eksik neredeyse tamamı) büyük bölümü "Büyükşehir belediyesi statüsüne geçilmesinin ardından su faturalarından şikâyetler artmıştır" ifadesine katılmaktadırlar. Buna karşılık 9 muhtar bu ifadeye katılmazken, 5 muhtar da kararsizdır.

Muhtarların (16 kişi) ve belediye yöneticilerinin (12 kişi) büyük bölümü "Köyden dönüşen mahallelerde ulaşımla alakalı sorunlar yaşanmaktadır" ifadesine katılmaktadır. Buna karşılık 7 muhtar katılmazken, 5 muhtar da kararsızdır.

Muhtarları (26 kişi) büyük bölümü "Büyükşsehir ve ilçe belediyeleri arasındaki siyasi çekişmeler ilçe belediyelerinde hizmet sunumunu olumsuz etkilemektedir" ifadesine katılmazken, belediye yöneticilerinin (16 kişi) büyük bölümünü bu ifadeye katıldıkları ve büyükşehir ve ilçe belediyeleri arasındaki siyasi çekişmelerden rahatsız oldukları anlaşılmaktadır.

Muhtarları (20 kişi) büyük bölümü “Tüzel kişiliği kaldırılan belde ve köylerde yaşayanlarda aidiyet sorunu yaşanmaktadır" ifadesine katılmazken, belediye yöneticilerinin (11 kişi) büyük bölümünü bu ifadeye katıldıkları görülmektedir.

Muhtarları (11 kişi) ve belediye yöneticilerinin (11 kişi) büyük bölümü "Büyükşehir Belediyeleri ilçelerde yerel hizmet ofisleri açmalıdır" ifadesine katılmakla beraber, bu ifadeye katılmayan muhtarların oranı (10 kişi) ve kararsızların oranı (7 kişi) oldukça yüksektir. Diğer yandan belediye yöneticilerinde de kararsızların oranı (6 kişi) fazladır. 
Çalışmada İncirliova Belediye Başkanı Gürşat Kale ile mülakat da gerçekleştirilmiş ve 6360 sayılı kanunla alakalı görüşlerine başvurulmuştur. Özetle başkan Kale İncirliova'nın merkeze yakın konumuyla avantajlı olmakla beraber, il merkezine yakınlık/uzaklığın yeni mahallelerde hizmet sunumunu ve dolayısıyla vatandaşın memnuniyetini etkilediğini belirtmekte; kanunun sorunlu veya eleştirilen taraflarını 6360 kapsamındaki il ve ilçelerin ekonomik sosyal vb farklılıklarını gözetmeden tek bir düzenlemeye, sadece nüfus gibi tek bir ölçüte bağlayarak ele alınması; kanunun herkesi şehirleştirme çabasına girmesi; tarım ve hayvancılığı olumsuz etkilemesi, kanunun içeriğinin idari ve teknik anlamda iyi düzenlenmemiş veya uygulama aşamasında vatandaşa iyi anlatılamamış olması, halkın muhatabını bilememesi veya bulamaması, kanunun ilçe beledilerini hizmet sunumunda teknik araç, ekipman ve yetersizliği ve özelllikle itfaiye teşkilatı anlamında güçsüz bıraktığı; nüfus artışına karşılık gelirlerin aynı oranda artmadığı, hatta azaldığı, köylerin mahalleye dönüşmesiyle köylerin az da olsa sahip olduğu mali yapı ve kendi ihtiyacını giderme kapasitesinin de ortadan kalktığı, dağ köylerine hizmet görümede zorlandıkları, büyükşehir ile ilçe belediyeleri arasında görev paylaşımının ve dolayısıyla gelir paylaşımının tekrar gözden geçirilmesi gerektiği şeklinde belirtmektedir. Başkan Kale ile yapılan röportajın bazı bölümlerine, verilen örneklerin orijinal olması nedeniyle aşağıda yer verilmektedir.

“6360 sayılı Büyükşehir Kanunu hakkında genel kanaatiniz nedir?” sorusuna cevaben Kale, 6360 sayılı kanunla il sınırının büyükşehir sınırı kabul edilmesiyle "Aydın merkeze uzak olan ilçeler ile yakın ilçeler arasındaki hizmet makası ciddi manada açıldı. Bizim ilçemizin merkeze yakın olması hasebiyle diğer ilçelere nazaran bir adım daha iyi diyebiliriz. Uzak ilçelerin zaman içerisinde merkeze uzak olmalarından kaynakl kendilerine has bir yaşam biçimleri oluştu. Yeni kanunla beraber eskiden beri devam eden bu yaşam biçiminden kopmak onlar için elbette zor olacaktır. Merkezle yani Büyükşehir yönetimi ile iç içe yaşamadıkları için hizmet yönünde sıkıntı çekeceklerdir." demekte ve il merkezine yakınlı/uzaklığın yeni mahallelerde hizmet sunumunu ve dolayısıyla memnuniyetini etkilediğini ifade etmektedir. Bu tespit literatürde konuyla alakalalı farklı çalışmalarda da dile getirilen bir duurumdur.

Kale 6360 düzenlemesinin sıkıntılı taraflarından bir başkasını ilçelerin ekonomik sosyal vb farklılıklarını gözetmeden tek bir düzenlemeye, sadece nüfus gibi tek bir kritere bağlayarak ele alınması olarak görmektedir: “..Her il ve ilçe aynı olmadĭ̆ için standart, tepeden inme bir kanunla genel bir manada çözüme ulaşmak istenilmektedir. Örnek vermek gerekirse....Mardin ve Ordu illerini incelediğimizde illerin kendi içinde bir ekonomik bütünlük olmadı̆ğn görüyoruz. Buna karşılık Istanbul ve Kocaeli illerinde kendi içinde bir ekonomik bütünlüğe sahiptir. Hal böyle olunca farklı özelliklere sahip illere aynı tarz bir yönetim uygulamayı doğru bulmuyorum.... Örnek vermek gerekirse Aydın için bir tarım politikası, hayvancılık politikası; Muğla için turizm politikası yerine ormancılık, tarım politikası çizelim. Bu yönetimler kendilerinin bildiği, kendilerine uygun olduğu politikaları belirlesin. Bunları biz uygulayalım. Biz tüm bunları yaparken Türkiye markasının ayrılmaz birer parçasıyız. Biz sadece coğrafi bölge olarak ekonomik ve sosyal birlikteliğimizi zedelemeyecek tarzda refahı arttırmak, milli geliri arttırmak amaçlı kısımlarını en üste çıkarmalıyız. Bunu özerklik, bağımsızllk ve başka şeyler konusunda ülke bütünlüğüne zarar vermeyecek tarzda merkezi olmak dışında bu konuyu daha ciddi tanımlamak gerekirdi. Sırf nüfusa bağll olarak bir yerin yönetimini değiştirmek, orayı Büyükşehir yapmak hiç doğru değildir."

Kanunun sıkıntılı yönlerinden bir başkası olarak başkan Kale, "Kanunun herkesi şehirleştirme çabasına girmesini” görmektedir. Kale'ye göre; “...tarımın, sanayinin ve turizmin olduğu bir bölgeyi bunların hepsinden yoksun bırakamazsınız. Çünkü dağdaki, ovadaki toprağın işlenmesi, sanayideki dükkanın çalışması gerekir. Siz köyde oturan bir vatandaşımızı şehre getirdiğinizde oradaki toprağı kim işleyecek? Vatandaşs şehirde oturup her gün köydeki yerine gidip toprağını ekonomik olarak işleyemez. Ailesiyle beraber köyde oturup toprağı işliyorsa, orayı canlı tutuyorsa orda oturmanın karşıllı̆̆ olarak onlara desteğin verilmesi şarttır. Onlara mazot desteği verilmesi, elektriğin ucuz verilmesi gibi destekler sağlanmall. Şehir ile köyde oturanın arasında bu tarz farklılıklar olmalıdır. ...Ama büyükşehir ile şuan ne oluyor? Vatandaşı köyde tutmak yerine onlara bir miktar para desteği sağlayıp köylerden şehirlere gö̧̧ etmeyi teşvik ediyorlar. Bu bir nevi milletin geleceğini sosyal yardım 
parasıyla satın almaktır. Şu anda büyükssehir yasası bizim hayattan beklentilerimizi karşılayamamaktadır."

Kale, kanunla ortaya çıkan olumsuzluklardan birini de 6360 sayılı kanunun içeriğinin iyi düzenlenmemiş veya uygulama aşamasında vatandaşa iyi anlatılamamış olması nedeniyle yeni düzenlemede halkın muhatabanı bilememesi veya bulamaması olarak görmektedir: "Şuan Incirliova belediyesinin sorumlu olduğu 28 mahallesi var. Bu mahallelerin ihtiyaçları konusunda bize gelen şikâyetlerin onda biri büyükşehir belediyesine iletilmiyor. Vatandaşın böyle bir alışkanlığı yok. Belediye olarak vatandaşın bize söylediği şey, seni biz seçtik. O halde bizim ihtiyaçlarımızı sen gider."

"Yeni büyükşsehir kanunu geldikten sonra şahıs veya belediye olarak yaşadığınız olumsuzluklar var mı? Varsa nelerdir?" sorusuna cevaben Kale, "Burada konuştuğumuz konu Aydın özelinde çok yeni bir yönetim tarzı ama ülke genelinde de nüfusun yüzde yetmişin muhatap olduğu bir düzendir. ...Bu yüzden ...büyükşsehir yasasının "bütünşehir" hali yeni uygulanacak olan illerde çok ciddi yönetim sorunu ortaya çıkarmıştır. Vatandaşımıza karş̧ bu konularda yeterli bir anlatım olmadı̆̆ için bizim gibi nüfusu az olan, etkileşimin direk temasla olduğu yerleşim yerlerinde insanlar kahvehanelerde birebir görüşmelerde kulaktan dolma bilgilerle hareket etmektedirler.... Dolayısıyla bunların her eve hatta her kişiye teker teker anlatılması gerekiyor."

Başkan Kale yeni düzenlemeye geçilmeden önce kanunun idari ve teknik altyapısının yeterince hazır olmadığını ifade etmektedir: “...kanunun fikri platformu iyi hazırlanmadi. Metin olarak iyi hazırlanmadiğl gibi uygulanması konusundaki öncelikleri de iyi irdelenmediği için birçok konuda sıkıntı yaşanmaktadır. Kanun yapıcı tüm bu sıkıntıları görmesine rağmen içinde yaşadı̆̆ımız bazı sorunların çözümüne belki ters düşecek diye bu rafta bekletiliyor. “

Kale "hazırlıksızlık" meselesini su faturalarının tahsilatı örneğinde açıklamaktadır: “.. göreve geldikten bir ay sonrasına kadar su fatura tahsilât işlemlerini belediye olarak biz gerçekleştirdik. Aydın ilinde ilçe bazında su tahakkuk işleminin durdurulması ve tahsilatlarının büyükşehre devredilmesi uygulaması bizden başladı. Bu işlemin kanun emri olmasına rağmen vatandaş bize niye bizim su parası almadığımızı, niye saatlere bakmadı̆̆ımızı, niçin kendilerinin sözünün dinlenilmediği şeklinde çok ciddi ifadelerde bulunmuşlardır. Insanlar işinin anında görülmesine baklyorlar. Onların bildikleri bu binanın üzerinde belediye yazlyor. Belediyeye gidilir, su alınır, karta doldurulur ve evde çeşme faaliyete geçer. Bunun sebebi ise ismen ASKI teşkilatının olup faaliyetlerinin olmamasından kaynaklanmaktadır. Bu idarenin görevidir. Bu sisteme geçilirken alt yapının tam manasiyla hazır olduğunu söylemek zor olur. ASKI hafta sonu çalışmadı̆̆ için, böyle bir zaruri ihtiyacın olduğunu önemsemediği için aksaklıklar yaşanmaktadır. Çünkü daha öncesinde bu işlem bizde iken cumartesi günü görevli arkadaşımız belediyede bulunurdu. Su ile sıkıntı olan vatandaşlarımıza yardımcı olmaya çalışırdı. “"

Kanunun literatürde de sıklıkla eleştirilen taraflarından biri olan teknik araç, ekipman ve yetersizliği ve özelllikle itfaiye teşkilatına ilişkin düzenlemeler, Kale tarafından da eleştirilmektedir: "...yangin, otobüs gibi hizmetler bizim belediyemiz tarafindan yapılan hizmetlerdi. Şimdi itfaiye teşkilatı komple büyükşehre geçti. Incirliova'da balkonda yaşamak genel bir yaşam tarzıdır. Böyle olunca evinin dişında kalan vatandaşlar itfaiyeyi arar, evine balkondan girerek bu sorunu hallederdi. Ama itfaiye büyükşsehre geçtikten sonra bu gibi sorunlarda itfaiyenin kullanılamayacağını söylemistir. Biz bunu altı ay vatandaşımıza anlatamadık. Büyükşehir bu konuda alternatif sunmadan bu sorunla bizi baş başa bırakt. Tam bu sırada vatandaşlarımızdan biri bizim bu sorunu halledebilmemiz adına bir araç hibe etti. Bizde bu şekilde vatandaşımızın bu tarz sorunlarını çözmeye başladık. Bu bizim birinci görevimiz değil ama büyükşehir bu tarz konularda pratik çözümler üretemediği için belediye olarak biz bunu kendimize vazife olarak gördük ve sorunun çözülmesi adına gerekenleri yaptık. "

Kale, kanunun gelirler, mali paylaşıma ilişkin hükümlerinin de sıkıntılı olduğunu ifade etmektedir: "Genel bütçeden bize aktarllan vergi gelirleri sıkıntımız var. ...2014 yılına kadar Iller Bankasından kişi başı gelen miktarl artmakta idi. Ama o tarihten sonra gelirlerde düşüs oldu. Nedeni ise Aydın'ın büyükşehir olmasından kaynaklanmaktadır. Daha önceden belediyemizin sorumlu olduğu 
alan $75 \mathrm{~km} 2$ iken büyükşehirle beraber $214 \mathrm{~km} 2$ 'ye çıkmıştır. Böyle olması demek ilçe nüfusunun artması demektir. Incirliova'nın nüfusu 2014'ten sonra 15,000 civarında artmıştır. Nüfus arttı ama iller bankasından bize gelen gelir 1/4 oranında azaldı. Bizim büyükşehir bütçesine katkımız il nazarında 1/20 oranındadır. Bu aktarılan gelirin çoğu iller bankasının bize vermiş olduğu kişi başı gelirdir. Böyle olunca ilçe belediyesi olarak bizim hizmet vermemiz zorlaşıyor. Nüfusumuz artıyor ama buna karşıllk belediyenin kasasına giren gelir miktarı azalıyor."

"Tüzel kişilikleri kaldırılan belde ve köyler ilçe belediyesine dâhil edildikten sonra ne gibi durumlar ortaya çıktı?” sorusuna cevaben Kale büyükşehir düzenlemesinin olumlu gördüğü tarafina dikkat çekerek, “...Büyükşsehrin tek faydası oldu. O da köy envanteri devlet envanterine sayısal ve nitelik olarak bir genel kontrol, genel sayım ve yerindelik tetkiki anlaminda devlet kılcal noktalarına kadar bilgi sahibi olmak adına önemli bir adım atıldı." demektedir.

Köylerin mahalleye dönüştürülmesi konusunda Kale'nin görüşleri genel olarak olumsuzdurr: “...bizim gibi tarım ve hayvancılık ile uğraşan yerlerde çözüm üretilmeye çalışılması kesinlikle faydamıza olmamıştır. Bu noktada köylerimizin çözülmesi gereken sorunlar ya erteleniyor ya da gündeme dahi alınmıyor. Çünkü tüzel kişilikleri ellerinden alındıkları için işin içine direk müdahil olamiyorlar. Muhtarlarda sadece bize mahallenin tercümanı olarak bize sorunların iletilmesini sağllyorlar. Bu durum köylerimiz adına bir kayıptır. Köylerinin sorunlarının bir kısmı kendi bütçeleriyle çözülüyor olması belediyelerin yükünü bir miktarda olsa hafifletebilirdi. ”

Kale köylerin mahalleye dönüştürülmesiyle ortaya çıkan sıkıntıları şöyle sıralamaktadır: "Belediyeler şu anda başta çöp olmak üzere pek çok konu ile o mahallelerin, o köylerin ihtiyaçlarını gidermekle görevlidirler. Bu konuda ilçemizin dışında diğer yerlerde ciddi sikıntılar yaşandiğını duyuyoruz. Özellikle dăg köylerinde haftada iki kere çöp toplayan tek belediye biziz. ...Ova köylerimizde de her gün çöp temizliği yapıyoruz. ...Ancak şunu belirteyim ki bu iş her şeyden önce maddi kaynakla alakalıdır. Maddi kaynak yeterli olmasa köylere hizmet götürme biraz daha zorlaşlyor. “

"Yeni yasa ile yetkilerinizin bir kısmı büyükşehir belediyesine devredildi. Sizin için en önemli olup devredilmesi belediyenize zarar verdi diyebileceğiniz yetki hangisidir?" sorusuna cevaben, "Kanun yapıcı bazı görevleri büyükşehir belediye meclisinin kararı ile ilçe belediyelerine devredilebilir diye yazmuştır. Devredilen yetkiler içinde bazllarının ilçe belediyelerine geri devredilmesi gerçekleşse dahi bunun kaynağını bize kanun gereği aktarımı sağlanamadığı için yine sorunlar yaşanmaktadır. Büyükşehir bize ilaçlama, defin ve mezbaha hizmetlerini verdi. Ancak bunun karşılığında hiçbir bütçe, kaynak aktarımı öngörmedi ve gerçekleştirmedi. Bunların yapılması ilçe belediyeleri tarafindan mümkündür. Ancak doğruluğu kalem kalem tartışllabilir"demekte ve imar planlama ve otopark örneğini vermektedir: “...İmar konusunda büyükşehir belediyesi yetkilidir. Ama uygulamanın yaşandı̆̆ yer ilçelerdir. İmar kanunu yapılacak apartman tipi yerlerde otopark zorunluluğu koşmuyor. Ama kanun otopark yapılırsa ödenmesi gereken harç miktarını büyükşehre yatırın diyor. Özellikle Incirliova gibi merkez ilçeye çok yakın barınma ihtiyacının giderek hızla arttı̆ğ böyle bir ortamda otopark ihtiyacı elzem bir durum haline gelmiştir. Türkiye gördügümüz gibi büyükşsehir yasaları ile şehirleştirilmektedir. Bunun karşıllğ̆ı olarak insanların hayatında araç, otomobil bir zorunluluk haline gelmeye başlamıştır. Bunların mutlaka hem can hem mal güvenliği açısından ayrıca şehir estetiği açısında ele alınması gerekmektedir. "İmar konusunda bizim tek başımıza hareket etmemiz mümkün değildir. Eskiden belediyeler tek başına imar plan tadilatları yapabiliyorlardı. Büyükşsehir yasası ile birlikte bunların müşterek olarak yapılması zorunlu kılınmıştır. Bizde şu an planlamalar içindeyiz ancak büyükşehirle beraber hareket etmekteyiz. “

Başkan Kale 6360 sayılı kanunun sorunlu yanlarının çözümü için “...ya eski hale dönüştürülmesi ya da mevcut büyükşehir yasasının uygulamasıyla birlikte çok radikal değişiklikler yapılarak yeniden düzenlenmesi gerekmektedir. Yerele özel olarak da ilçeleri içine katacak bir yönetim sistemi olması gerekmektedir" demektedir. Kale, "büyükşehir yasasının tüm maddeleri üzerinden adım adım gidilebilir. Ben burada büyükşehrin tüm maddelerini yaşıyoruz şeklinde bir 
iddiada bulunamam. Bunu turizm bölgesi olan Didim, Kuşadası gibi yerlerdeki uygulamalarl ile merkez ilçe olan Efeler için farklı uygulamalar söylenebilir. "

\section{Sonuç, Tartışma ve Öneriler}

6360 sayılı kanunla illerin idari yapısında, yerel yönetimlerin mali yapısında, katılım durumunda, yerel halka hizmet sunumunda ve üst planlama konularında mevcut yerel yönetim sisteminde önemli değişiklikler yaşanmıştır.

Büyükşehir olunmasıyla il çapında yapılacak planlamalarda bütünlügün sağlanması, yerel yönetimlerde parçalanmış idari alan ve bunun neden olduğu sorunların ortadan kaldırılması, planlamanın tek elden yapılması, yerel yönetim birimleri arasında koordinasyon ve tasarrufun etkin olarak sağlanması beklenmektedir. Kanunla kentin kamu yatırımlarından daha çok pay alması ve kente yapılacak yatırımların artması öngörülmektedir (Genç, 2014). Bununla birlikte dönüşümün temellendirilmeden, il büyüklükleri, nüfusu ve hizmet sunum hazırlıkları yapılmadan yürürlüğe girmesi bazı aksaklıkların yaşanmasına ve kamuoyunda "tam olarak başarı sağlanamadı" yargısının oluşmasında etkili olduğu söylenebilir.

Kanun geçiş döneminde yaşanabilecek sorunlara karş1 büyükşehir ve ilçe belediyelerine yatırım bütçelerinin en az \%10' unu on yıl süre ile altyapı hizmetleri için ayırmaları ve kullanmaları gerektiği görevi vermiş olmasına rağmen alandan elde edilen sonuçlar bu tedbirin yeterli olmadığını göstermektedir.

İncirliova özelinde alandan elde edilen sonuçlar göstermektedir ki, büyükșehir belediyesi sınırlarının, il sınırlarına kadar genişlemiş olmasının vatandaşa daha etkin hizmet sunulmasında; belediyenin sorumluluk sahasının genişlemesinin hizmet sunumunda; eski köyler/yeni mahallelerin ilçe merkezine uzak olmasının hizmet sunumunda; eksi köyler/yeni mahallelerin ilçe merkezi ile arasında coğrafi engellerin hizmet sunumunda; büyükşehir ve ilçe belediyeleri arasındaki siyasi çekişmelerin ilçe belediyelerinde hizmet sunumunda olumsuz etki yaptığı katılımcılar tarafından ifade edilmiştir. Verilere göre geleneksel yerleşim yeri olan köylerin bu kanundan kısa vadede olumsuz etkilendikleri sonucuna ulaşmak mümkündür.

6360 sayılı kanunla belediyelerle benzer nitelikte hizmet üreten tüzel kişilikler ve birliklerin kaldırılması kaynak ve personel tasarrufu ile yönetim bütünlüğü açısından olumlu olmakla beraber, araştırmaya katılanların çoğunluğu bu görüşü benimsemedikleri, belde belediyelerine, köylere ve il özel idarelerine tüzel kişiliklerinin geri verilmesi gerektiğini ifade etmektedirler.

Kuşkusuz mali durum hizmet sunumunu yakından etkilemektedir. Çalışmada yeni kanunla İncirliova Belediyesinde sorumluluk alanının genişlemesine bağlı olarak artan nüfus ile kaynakta görünürde artışın yaşandığı, fakat uygulamada kesintilerden sonra mali kaynağın kanun öncesi duruma göre düştüğü tespit edilmiştir. Bu itibarla Belediye Gelirleri Kanununun da revize edilmesi gerektiği değerlendirilmektedir.

Katılımcılar, büyükşehir kanunu yürürlüğe girmeden önce görüşlerinin alınması ve kanunun gerekçelerinin anlatılması gerektiğini ifade etmişlerdir. Ayrıca kanunla yeni bir katılım mekanizması, karar almada yeni bir ölçek veya yerindenlik ilkesi açısından bir yenilik getirmediği (Koyuncu ve Köroğlu, 2012), tersine hizmet sunumunda vatandaşa en yakın kamu örgütleri olan ve küçük ölçekleri nedeniyle katılımcılığın en iyi uygulanacağı köy ve belde belediyeleri tasfiye edilerek Avrupa Yerel Yönetimler Özerklik Şartı'nın yerindenlik ilkesi ile çelişen bir durumun ortaya çıktığı literatürde de ifade edilmektedir.

Etkin hizmet için uygun ölçeğin ne olacağını tespit etmenin zor olması özellikle tarım kenti olan İncirliova'nın dolayısı ile Aydın ili için optimal ölçeğin ne olduğu, mevcut kanunun kırsal alanlarla ilgili bir düzenlemeye yer vermemesi, kanunun mera alanları ve tarım hayvancılık için muafiyet sağlaması gibi konuların çözümünü ileriye ötelediğini göstermektedir. Ölçekten kaynaklanan sorunları çözmek için var olan yerel yönetimlerde değişiklik yapılmadan birleştirmeler ve birlikler kurulmas1 (Genç, 2015) alternatifleri 6360 sonrası dönemde yeniden değerlendirilmelidir.

Alan araştırması esnasında iki muhtarlıktan hizmet etkinliğinin arttırılması için öneriler gelmiştir. Bunlardan ilki, 'Köylere Hizmet Götürme Birlikleri yeniden yapılandırılarak muhtarlara yetki verilir ve köyün nüfusu oranında kaynak aktarılır ise büyükşsehirlerin yükü azalır ve etkinlik arttırılır." şeklindedir. Diğer öneri ise "Köylere tüzel kişilik verilerek ilçelere bağlanabilir. Yetkiler tekrar düzenlenerek imar, altyapı gibi planlama gerektiren konular büyükşehirde kalır, diğer işlemler 
(nikâh defin gibi) muhtarlığa verilebilir.’’ şeklindedir. Anket sonuçlarında olumsuz görüşlerin ortaya çıktığı konuların, kanunun tam anlamıyla uygulanmasıyla sonuçlarının zaman içinde şekilleneceği değerlendirilmektedir. 


\section{Kaynaklar}

Adıgüzel, S. (2012). 6360 sayılı yasanın Türkiye'nin yerel yönetim dizgesi üzerine etkileri: Eleştirel bir değerlendirme. Toplum ve Demokrasi, 6 (13-14), 153-176.

Aydın Büyükşehir Belediyesi meclis kararları. (2017). 12.03.2017 tarihnde http://aydin.bel.tr/detail/ 5010/16042014-tarihli-belediye-meclisi-kararlari adresinden erişilmiştir.

Aydın Büyükşehir Belediyesi kentte tarım. (2017) 27.02.2017 Tarihinde http://aydin.bel.tr/ detail/4380/kentte-tarim adresinden erişilmiştir.

Bahadır, G. (2017). 6360 sayılı büyükşehir yasanın muhtarlıklar üzerine sosyo-ekonomik etkileri üzerine bir araştırma: Vakfikebir/Trabzon örneği. Yayımlanmamış Yüksek Lisans Tezi, Avrasya Üniversitesi, Sosyal Bilimler Enstitüsü, Trabzon.

Genç, F. N. (2014). 6360 sayılı kanun ve Aydın'a etkileri. Adnan Menderes Üniversitesi Sosyal Bilimler Enstitüsü Dergisi, 1, Özel Sayı, 1-29.

Genç, F. N. (2015). Belediyelerin temel sorun alanları. İçinde Mehmet Mecek, Mesut Doğan , Bekir Parlak (Ed.), İdari ve mali açıdan Türkiye'de yerel yönetimler, (275-309), Ankara: Bekad Yayınları.

Genç, F. N. ve Daşçı, A. (2016). 6360 sayılı kanunun kamu hizmetlerinin sunumuna etkisi: Balıkesir büyükşehir belediyesi örneği. Journal of Social and Humanities Sciences Research, 6 (2), 132.

İncirliova Belediyesi (2016) Incirliova Belediyesi Faaliyet Raporu.

Karayel, Y. E. (2016). 5227 sayll kanunun incelenmesi ve bu kanunun öngördüğ̈̈ yerelleşme sisteminin 6360 sayılı kanunla karşılaştırılması, Yayımlanmamış Yüksek Lisans Tezi, Muş Alparslan Üniversitesi, Sosyal Bilimler Enstitüsü, Muş.

Koyuncu, E. ve Köroğlu, N. T. (2012). Büyükşehir tasarısı üzerine bir değerlendirme, http://www.tepav.org.tr/upload/files/13524625179.Buyuksehirler_Tasarisi_Uzerine_Bir_Dege rlendirme.pdf, 17.03. 2017

Sezik, M. (2015). 6360 sayıl kanun'a göre büyükşehirlerde bütünleşme sürecinin etkileri: Malatya örneği, YayımlanmamışYüksek Lisans Tezi, İnönü Üniversitesi, Sosyal Bilimler Enstitüsü, Malatya.

TUiK (2016). Adrese dayalı nüfus sistemi. 20.02.2017 tarihinde https://biruni.tuik.gov.tr/medas/?kn=95\&locale=tr adresinden erişilmiştir.

Yerel Yönetimler Portalı (2017). 20.02.2017 tarihinde http://www.yerelnet.org.tr/ ilceler/ilce_koy_koordinat.php?ilceid=198315 adresinden erişilmiştir.

Yıldırım, U., Gül, Z. ve Akın, S. (2015). İl mülki sınırı büyükşsehir belediye modelinin getirdiği yenilikler. Eskişehir Osmangazi Üniversitesi İ̈BF Dergisi, 10(2), 205-229.

Zengin, O. (2014). Büyükşehir belediyesi sisteminin dönüşümü: son on y1lın değerlendirmesi, 2014/2, Ankara Barosu Dergisi. 


\section{Extended abstract}

With the law no.5216 issued in 2004, the introduction of the new metropolitan municipality model covering all of the provincial property borders, strengthening of this model with the law no.5747 issued in 2008, and with the laws no.6360 and 6447 adopted in 2012, extension of this model to all metropolitan municipalities, has led to significant changes in the metropolitan system in Turkey.

In the new model introduced with the law no.6360, the application area of the metropolitan municipality was determined as the province scale and a local government structure to integrate the metropolitan municipality, municipality, village and province special administrations was introduced and the metropolitan municipalities were provided with the opportunity to administrate a large space covering the whole area of the province, and therefore spatial area management has been introduced. In the provinces where this model will be implemented, it is aimed that the legal entity of some local government units will be removed and that the metropolitan municipalities will be the only authorized unit in these administrations (Y1ldirım et al., 2015: 223). The consequences of this change in public service provision will be seen in a concrete structure in the process.

Law no. 6360 changed the definition of the "metropolitan". According to the new law, the metropolitan municipality expresses "the public legal entity whose borders are the provincial property borders and which are coordinated between the county municipalities within their borders, who use the authorities, fulfill the duties and responsibilities given by law with administrative and financial autonomy, (Article.4). According to the definition, the borders of the metropolitan municipality cover the borders of provinces. The new law stipulates that the total population of the province will be taken into consideration by the regulation of "the provinces with more than 750,000 total population can be transformed into metropolitan cities by law", by the population required for the establishment of the metropolitan municipality. An examination of the current state among the local people and administrators brought by the changes that the law makes to the provision of public services takes place in the literature.

Aydin is also one of the provinces that have become a metropolitan with the law No.6360. By the enforcement of the Law on the Metropolitan Municipality, a task sharing was made between Aydin Metropolitan Municipality and the district municipalities. According to this, the district municipalities shall undertake the license works of the whole district area, the services of park gardens and squares under $4000 \mathrm{~m} 2$, the road works of streets and streets with a width of up to 12 meters in the zoning plan, pavement construction, repair and cleaning services, marriage services, pest control and cemetery and burial services in the district area.

İncirliova District of Aydin Province constitutes the subject of this study. In this context, the question for that an answer is sought in this study is whether the expected results (efficiency, efficiency, zoning, integrity in transportation and infrastructure planning, staff and resource saving, coordination ease etc.) arising from the implementation of the metropolitan model based on the metropolitan municipality law no. 6360 from the point of view of the former and current muhtars in İncirliova district.

Although there are studies conducted related to the Law No. 6360, which was adopted in 2012 and applied since March 2014, there are few studies based on the field research among them (Adigüzel (2012), Genç (2014), Zengi (2014), Sezik (2015), Daşcı and Genç (2016), Karayel (2016), Bahadır (2017), Genç, F.N., Korkin E. (2017).

There is no study done on the Incirliova District in the within the frame of Law No. 6360.

While the universe of the study is constituted by the 30 metropolitan municipalities that have obtained the status of the metropolitan municipality with the law no. 6360, the sample is constituted by the Incirliova municipality of Aydin Province. The study was carried out in the district of Incirliova, by using interview forms and a Likert type ( 3 options) questionnaire, addressed to a group of 46 people, consisting of neighborhood muhtars (former and new muhtars, 28 in total), mayor, deputy mayor and councilmen (18 in total). The questionnaire consists of 54 questions, 9 of which are demographic questions, and 45 of which are research questions.

The results from the questionnaires are as follows; most of the muhtars, mayors, deputy mayors and municipal councilors share the same opinion mostly, except for a few statements in the questionnaire and interview form, and they often have negative opinions about the implementations of the Law No.6360. 
Much of the muhtars and municipal administrators are thinking that the fact that the borders of the metropolitan municipalities have expanded to the provincial borders has not been a positive development in terms of providing more efficient service to the citizens; that they don't regard the conversion of the villages/townships to the neighborhoods of the metropolitan municipality (province), the closure of special provincial administrations and the unions of local governments within the borders of the metropolitan municipality (province); the transition to the metropolitan status does not provide zoning and planning integrity; the fact that the borders of the metropolitan municipalities have expanded to the provincial borders have not been seen as a positive development in terms of providing more efficient service to the citizens; the transition to the metropolitan status does not reduce the cost of services; that they do not find the works of the Directorate of Investment Monitoring Coordination favorable; that the metropolitan status does not strengthen administration-citizen relations; that they do not find the establishment of new municipalities positive; that the efficiency of the local services provided in the county has not increased since the introduction of the metropolitan regulation; that it is not easier for the people of the district to access local public services and coordination between the district municipalities does not increase.

In addition, municipal administrators say; switching to the metropolitan status have increased the correspondence/bureaucracy and complaints from water bills; that there are problems related with transportation in the neighborhoods turning into villages; the financial autonomy of the district municipalities is decreased and the dependence on the metropolitan municipality is increased; the cause of the extension of the municipality's responsibility area is causing disruption in the provision of services; the possibility of representation of the district municipalities is reduced by the introduction of the metropolitan administration; after the metropolitan regulation, the public's complaints about the infrastructure have increased; the complaints about transportation and zoning regulations in the province after the metropolitan regulations, have increased; problems of coordination between the metropolitan municipality and the district municipalities, problems of the distribution and implementation of the authorities of the metropolitan municipality and zoning authorities and problems in terms of personnel, technical equipment, tools and equipment for providing service to former villages/new neighborhoods, have been experienced. Moreover, the municipal administrators also think that the metropolitan regulations are not compatible with local democracy; the provision of the services are affected negatively by the remoteness of the former villages/new neighborhoods and the geographical obstacles between them and the centrum; the effectiveness of the services has been decreased by the conversion of villages into neighborhoods, agriculture and livestock is affected negatively, the centralization is increased by the metropolitan regulations; there are problems experienced regarding the provision of service, especially to former forest villages; it should be reversed to the status prior to the metropolitan model; metropolitan municipalities should open local service stations in the districts; a new arrangement of the distribution of income from the public tax budget between the metropolitan and the district municipalities should be made; and the legal entities of the townships should be re-instated. 